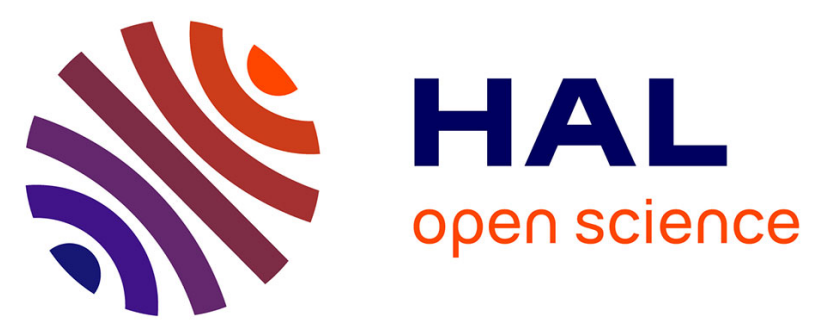

\title{
Judging health risk as a function of risk factors and type of illness: Do people weight risk factors in a flexible way?
}

Myriam Guedj, Etienne Mullet, Anne Cambon-Thomsen

\section{To cite this version:}

Myriam Guedj, Etienne Mullet, Anne Cambon-Thomsen. Judging health risk as a function of risk factors and type of illness: Do people weight risk factors in a flexible way?. Journal of Health Psychology, 2016, 21 (5), pp.832-843. 10.1177/1359105314539532 . hal-01926515

\section{HAL Id: hal-01926515 \\ https://hal-univ-tlse2.archives-ouvertes.fr/hal-01926515}

Submitted on 19 Nov 2018

HAL is a multi-disciplinary open access archive for the deposit and dissemination of scientific research documents, whether they are published or not. The documents may come from teaching and research institutions in France or abroad, or from public or private research centers.
L'archive ouverte pluridisciplinaire HAL, est destinée au dépôt et à la diffusion de documents scientifiques de niveau recherche, publiés ou non, émanant des établissements d'enseignement et de recherche français ou étrangers, des laboratoires publics ou privés. 


\section{Author Queries}

$\begin{array}{ll}\text { Journal title: } & \mathrm{HPQ} \\ \text { Article Number: } & \mathbf{1 0 . 1 1 7 7 / 1 3 5 9 1 0 5 3 1 4 5 3 9 5 3 2}\end{array}$

Dear Author/Editor,

Greetings, and thank you for publishing with SAGE. Your article has been copyedited, and we have a few queries for you. Please respond to these queries when you submit your changes to the Production Editor.

Thank you for your time and effort.

NOTE: Please answer the queries by editing within the article: follow the AQ hyperlink below and edit the text directly. Add a "New Comment" (in the "Review" tab), if the correction cannot be done directly or for further queries.

Below, please tick the boxes to the right of the query, to indicate the query has been dealt with.

Please assist us by clarifying the following queries:

\begin{tabular}{|c|c|c|}
\hline$\underline{\mathrm{AQ1}}$ & Please check whether the author names and affiliation details are correct as set. & $\underline{\mathrm{x}} \square$ \\
\hline$\underline{\mathrm{AQ} 2}$ & Please check whether the corresponding author details are complete and accurate as set. & $\underline{\mathrm{x}} \boxminus$ \\
\hline$\underline{\mathrm{AQ} 3}$ & $\begin{array}{l}\text { 'Källberg et al. (2010)' has been changed to 'Källberg et al. (2011)' to match the reference list. } \\
\text { Please check and confirm. }\end{array}$ & $\underline{x} \boxminus$ \\
\hline$\underline{\mathrm{AQ} 4}$ & $\begin{array}{l}\text { 'Kulbertus and Lancellotti (2013)’ has been changed to 'Kulbertus and Lancellotti (2012)' to match } \\
\text { the reference list. Please check and confirm. }\end{array}$ & $\underline{x} \boxminus$ \\
\hline$\underline{\mathrm{AQ} 5}$ & $\begin{array}{l}\text { 'Marshall and Christiani (2013)' is not listed in the references. Please provide reference details or } \\
\text { delete the citation. }\end{array}$ & $\underline{x} \boxminus$ \\
\hline$\underline{\mathrm{AQ6}}$ & Please check whether the edits made to the sentence 'We will assess the ...' are correct. & $\underline{x} \boxminus$ \\
\hline$\underline{\mathrm{AQ7}}$ & Please confirm whether the given funding statement is correct. & $\underline{x} \boxminus$ \\
\hline$\underline{\mathrm{AQ} 8}$ & Please check whether the inserted details are correct for 'Igier et al. (2014)'. & $\underline{\mathrm{x}} \boxminus$ \\
\hline$\underline{\mathrm{AQ} 9}$ & $\begin{array}{l}\text { 'Muñoz Sastre et al. (2002)' is not cited in text. Please indicate where a citation should appear or } \\
\text { delete the reference. }\end{array}$ & $\underline{x} \boxminus$ \\
\hline$\underline{\mathrm{AQ} 10}$ & $\begin{array}{l}\text { Please note that 'Smerecnik et al. (2009)' was listed twice in the references; hence, one of the } \\
\text { occurrences has been deleted. Please check. }\end{array}$ & $\underline{x} \boxminus$ \\
\hline$\underline{\mathrm{AQ11}}$ & Please check whether the inserted details are correct for 'Sobenin et al. (2013)'. & $\underline{\mathrm{x}} \boxminus$ \\
\hline$\underline{\mathrm{AQ} 12}$ & $\begin{array}{l}\text { Please note that 'Vandelanotte et al. (2011)' was listed twice in the references; hence, one of the } \\
\text { occurrences has been deleted. Please check. }\end{array}$ & $\underline{\mathrm{x}} \square$ \\
\hline
\end{tabular}





\title{
Judging health risk as a function of risk factors and type of illness: Do people weight risk factors in a flexible way?
}

Journal of Health Psychology 1-12

(C) The Author(s) 2014

Reprints and permissions:

sagepub.co.uk/journalsPermissions.nav DOI: $10.1177 / 1359105314539532$ hpq.sagepub.com

\author{
Myriam Guedj ${ }^{1}$, Etienne Mullet ${ }^{2}$ and \\ Anne Cambon -Thomsen ${ }^{3}[\mathrm{AQ} 1]$
}

\begin{abstract}
We examined the extent to which lay people arlabalth professionals are able to assess occurrence risks for multifactorial diseases. We asked 341 participants to assess the risk of developing lung cancer, coronary artery disease or rheumatoid arthritis in 16 scenarios, each featuring a combinationuoffdctors (family history, daily alcohol intake, daily tobacco consumption and genetic test results). Participants considered all factors. However, they accorded more weight to tobacco and genetic test results. Moreover, it appears that where one of theactors (e.g. the presence of the incriminated gene) exerted a strong influence, the influence of the other factor(s) was correspondingly weaker. The health risk judgements of health professionals were more dependent on the specific disease and were afkæinced to a greater degree by genetic information than lay people.
\end{abstract}

\section{Keywords}

coronary artery disease, genetic susceptibility, health behaviour, health risk assessment, lung cancer, rheumatoid arthritis

\section{Introduction}

As more and more risk factors emerge as probable causes in disease aetiology, the question of how they interact, be it through synergy (positive interdependence) or through antagonism (negative interdependence), is increasingly important (Rothman, 1976). For most common diseases, there are nearly always some genetic and environmental component causes. In other words, virtually every case of every disease has some environmental and genetic component causes and can thus be attributed both to genes and to the environment
(Rothman, 1976; Rothman and Greenland, 2005). For example, rheumatoid arthritis (RA) develops mainly because of certain genes

\footnotetext{
${ }_{4}^{1}$ Université Toulouse II - Le Mirail, France

${ }^{2}$ Ecole Pratique des Hautes Etudes, France

${ }^{3} \mathrm{U}$ 1027, UMR Inserm, Université Toulouse III - Paul

Sabatier, France

Corresponding author: [AQ2].

Myriam Guedj, OCTOGONE-CERPP, Pavillon de la Recherche, Université Toulouse II - Le Mirail, 5 Allées Antonio Machado, 31058 Toulouse Cedex $\underline{9}$, France.
}

Mis en forme : Français (France)

Mis en forme : Français (France)

Mis en forme : Français (France)

Mis en forme : Français (France)

Code de champ modifié 
(Chibnik et al., 2011), but tobacco consumption can also influence the risk of the disease developing in at-risk patients (Bang et al., 2010; Källberg et al., 2011; Lahiri et al., 2012).[AQ3] Similarly, the major risk factor for the development of lung cancer is cigarette smoking, but multiple genetic factors may also play a role (Marshall and Christiani, 2013; Molina et al., 2008; Myneni et al., 2013; Wang et al., 2013), while coronary artery disease is the result of harmful interactions between genetic and environmental factors such as smoking, poor diet, lack of exercise and alcohol consumption (Gränsbo et al., 2013; Kulbertus and Lancellotti, 2012; Pun et al., 2013; Sobenin et al., 2013).[AQ4] [AQ5]

Clinical epidemiology is about examining risk factors in conjunction with each other in order to arrive at a correct assessment of overall health risks. However, the way in which people draw all this information together can run counter to good epidemiological practice. An example of the discrepancy between the objective epidemiological model and people's mental models is provided by Hermand et al. (1997), who asked 64 participants to estimate the level of cancer risk in a number of situations where tobacco consumption was associated with that of alcohol. Although the participants were generally aware that the consumption of tobacco and alcohol can have a serious impact on the level of cancer risk, instead of representing the combined effects of tobacco and alcohol consumption in a summative or synergistic way, they apparently considered that indulging highly in just one of these two dangerous behaviours is enough to result in a maximum risk of cancer: A heavy smoker was thought of as not having much to lose if he or she was also a heavy drinker. Similarly, a heavy drinker was also thought of as not having much to lose if he or she was a heavy smoker. Their perception of how the effects of the two substances interact corresponded to Rothman's (1976) antagonism model. It was, however, in complete contradiction with their answers to a questionnaire, which revealed their knowledge to be almost scientific (see, for example, Kozlowski and Ferrence, 1990; Rosengren et al., 1988; Saracci, 1987). Another example is the discrepancy between people's awareness of cardiovascular disease and their failure to perceive themselves as being at risk: In women attending a cardiovascular health-screening event, 99 per cent were aware that cardiovascular disease is the leading cause of death among women. However, only approximately half (47\%) perceived themselves to be at personal risk, even though 65 per cent were determined to be 'at risk' and 12 per cent at 'high risk' according to guidelines. Of the 228 participants, 'at risk' or 'high risk' 48 and 21 per cent, respectively, did not perceive themselves to be at risk at all (Kling et al., 2013).

Other studies have reported similar misconceptions regarding the combined effect of health risks, with cases of risk underestimation associated with weight (Vandelanotte et al., 2011), cancer (Mattson et al., 1987; University of California at Berkeley, 2007), cancer and heart disease (Ayanian and Cleary, 1999) and hookah smoking (Noonan and Patrick, 2013).

Nevertheless, people can be taught to draw together information relating to diverse health risks, and simple techniques have proved successful in teaching lay people how to employ the synergetic combination model. For example, Bonnin-Scaon et al., (2002) examined the effect of outcome feedback on training to develop the ability to assess the multiplicative relationship between daily intakes of tobacco and alcohol, and the risk of oesophageal cancer. In the first of two experiments, 65 French adults assessed the risk of oesophageal cancer associated with a combination of five different levels of tobacco and five of wine. They assessed them both before and after training sessions in which they were shown the actual risk for each vignette. In the second experiment, 35 French adults underwent the same evaluation and training and were reassessed a month later. Results indicated that 
prior to the training sessions, the participants used a subadditive rule to combine the perceived risks of oesophageal cancer due to smoking and drinking. After just one training session, they changed to the multiplicative rule consistent with epidemiological data. However, only a limited range of risk factors were examined in this study, and none of them were genetic. Of the few studies of genetic factors that have been conducted among the general population, one has indicated that when genes and behaviour are presented as being damaging to health, the majority of the population adopts an additive model (with approximately onethird adopting an amplifying model). In the gain frame (genes and behaviour presented as being health-protecting), assessments are divided roughly equally between additive, amplifying and subadditive models (Condit and Shen, 2011). Other studies have highlighted misconceptions about the results of the directto-consumer genetic tests (Leighton et al., 2012), and misconceptions also appear when the genetic and environmental causes of breast and colorectal cancer are studied (Wang et al., 2010). In the case of cardiovascular disease, people produce fatalistic responses and believe that little can be done to reduce the risk when genetic risk information (vs family history and/or cholesterol testing) is provided (Claassen et al., 2010).

Other research has studied the perceptions of focus groups (e.g. at-risk groups in the population, patients or patients' relatives). The impact of genetics varies according to the study and the disease under scrutiny. All participants with relatives who are alcoholics, for instance, attribute the alcoholism in their families to multiple factors - often a combination of biological, genetic and environmental ones - as well as to personal characteristics (Gamm et al., 2004). Among those at risk of cardiovascular disease, findings suggest that family history may be more important than DNA information when it comes to explaining perceptions of and responses to risk (Claassen et al., 2012). Among the overweight participants with a high phenotypic risk of Type-2 diabetes, an exploration of perceptions of genetic risk testing for diabetes, compared with currently available prediction methods based on non-genetic risk factors (e.g. family history, abnormal fasting blood glucose levels and obesity), revealed that many participants 'conferred a unique value' on information about their genetic risk, that is, they considered only the genetic risk in the risk to develop the disease (Markowitz et al., 2011). Similarly, a study examining risk perceptions among patients with an increased risk of cancer showed that prior to genetic counselling, all the participants estimated their risk as being higher than it actually was (Rantala et al., 2009). Furthermore, in a review of the impact of genetic counselling on risk perception, results suggested that 'genetic counseling may have a positive impact on the accuracy of risk perception' (Smerecnik et al., 2009).

\section{This study}

This study examined whether lay people are able to adjust their weighting of risk factors when judging the overall risk of developing a given illness. In other words, we examined the extent to which lay people are able to use the information available to them in a flexible way, attributing more weight to one risk factor (e.g. tobacco consumption) in one situation (e.g. judging the risk of developing lung cancer) and less weight to this same factor in another situation (e.g. judging the risk of contracting arthritis). This study also compared lay people's flexibility in weighting up risk factors with that of health professionals.

We should emphasize that the question examined in this study was not whether lay people mentally combine information in a correct and optimum way. Posing such a question would be largely meaningless because the answer is obviously no. We already know that people do not combine health risk information in an optimum way, because if they were able to do so, there would have been no need to develop the branch of medical science known as epidemiology. The very existence of 
epidemiology is direct proof of people's inability to combine risk information in an optimum way. Rather, this study was about the way people actually use and combine information. We simply wanted to know whether they are sensitive to risk factors (e.g. family history), whether they use them in a reasonable way (e.g. in the right direction), and whether they bear in mind the diversity of everyday life situations when using and combining information that corresponds to these risk factors.

This study, like many previous ones (e.g. Guedj et al., 2005; Igier et al., 2014), featured a set of scenarios, that is, participants were instructed to consider actual cases, indicating for each one the extent to which a given health risk was repeated. Three very different illnesses were considered: (a) lung cancer, known to be strongly associated with people's behaviour and environmental conditions; (b) RA, known to depend mainly on genetic factors and (c) coronary artery disease, known to depend on both sets of factors. The risk factors involved in the scenarios were those most commonly encountered in the literature on health risk assessments: (a) daily alcohol intake (no drinking habit vs heavy drinking habit), (b) daily tobacco consumption (non-smoker vs heavy cigarette smoker), (c) a history of illness in the family (uncle vs father) and (d) the results of a genetic test (presence vs absence of a specific gene). In summary, two of the risk factors were behavioural (alcohol intake and tobacco consumption) and two were genetic (family history and genetic test). We will assess the weight of the genetic factor in our study by using genetic test, although they are not currently used in medical practice.[AQ6]

\section{Hypotheses}

Our first hypothesis was that all four risk factors would be used by the participants to judge the overall risk of contracting each illness. They would judge the overall risk to be higher in the presence of each of the risk factors (heavy drinking, heavy smoking, a genetically close family relative with the illness or the detection of the incriminated gene) than in the opposite case.

Our second hypothesis was that some of the risk factors at least would be used in an interactive way. This hypothesis was based on the findings from earlier studies showing that when lay people judge the risk of cancer on the basis of daily alcohol intake and tobacco consumption, they mentally combine the two factors in a disjunctive way, that is, when the weight of a factor prevails over the other (see also, Bonnin-Scaon et al., 2002; Hermand et al., 1997). We, therefore, expected to observe an Alcohol $\times$ Tobacco interaction and envisaged the possibility of a Tobacco $\times$ Gene interaction, too.

Our third hypothesis was the central hypothesis in this study. We expected to observe several interactions between the four factors and the three types of illness. More specifically, we expected (a) more weight to be attributed to the two behavioural risk factors (alcohol and tobacco) for lung cancer than for RA and (b) more weight to be attributed to the two genetic risk factors (family history and genetic test) for RA than for lung cancer. We also expected the results for coronary artery disease to be midway between the ones observed for the other two illnesses. We, therefore, expected to see several Risk factor $\times$ Type of illness interactions.

Our fourth hypothesis was that the health professionals would display greater flexibility in the weighting of the risk factors than the lay people. Accordingly, we expected to see several Participant group $\times$ Risk factor $\times$ Type of illness interactions.

\section{Method}

\section{Participants}

The lay people were approached and recruited by two trained research assistants in the city centre of Toulouse and the region of Midi- 
Pyrenees in south of France. Some 500 people were contacted altogether, and after receiving a full description of the procedure, 54 per cent of them agreed to take part. The professionals were contacted in workplace, in the clinics and hospitals of Midi-Pyrenees. All 341 participants (197 women, 144 men) were unpaid volunteers. They were informed about the goals of the study and asked to provide their written informed consent. Their mean age was 41.3 years (standard deviation $(S D)=13.52$ years, $\quad$ range $=13-86$ years $)$. They included 271 lay people, 64 nurses and 6 physicians.

Of the 271 lay people, 50.44 per cent had a university degree and 49.56 per cent had completed secondary education but did not have a university degree.

\section{Material}

The material consisted of 16 cards for each disease, each bearing a brief description of a scenario, followed by a question, and a response scale. The scenarios were constructed according to a four within-participant factor design, and the information was presented in the following order: (a) daily alcohol intake (practically no intake vs heavy drinking), (b) daily tobacco consumption (non-smoker vs heavy cigarette smoker), (c) history of illness in the family (uncle vs father) and (d) the results of a genetic test (presence vs absence of the incriminated gene). Sex and age were held constant: all the patients were aged about 45 years and identified as ' $\mathrm{Mr}$ '.

The question was 'In your opinion, what is the risk of $\mathrm{Mr} \mathrm{X}$ developing [name of illness]?’. Participants had to rate their responses on a 15point scale ranging from 1 (No risk at all) to 15 (Very high risk). Two examples are provided in Appendix 1. The cards were presented in a different random order for each participant.

\section{Procedure}

The experiment took place in a single session, held in a vacant room in the hospital, the university or in the participant's home. Each person was tested individually. As recommended by Anderson (1982), the session came in two phases. In the first, familiarization phase, the participants were told by the person conducting the interview what was expected of them and presented with eight scenarios taken from the complete set of 16. They then provided a risk rating for each case. After completing the eight ratings, the participants were given the opportunity to review their responses and modify them.

In the experimental phase, all 16 scenarios were presented three times: once in the lung cancer condition, once in the coronary artery disease condition and once in the RA condition. The conditions were presented in a different random order for each participant. The participants were allowed to provide their ratings at their own pace but were no longer allowed to review their responses or go back and change them as they had done in the familiarization phase. In both phases, the experimenters routinely checked that each participant, regardless of age or educational level, was able to grasp all the necessary information before producing a rating.

It took the participants 20-40 minutes to complete the familiarization phase and all three sets of scenarios. The experimental phase went quickly because the participants were already familiar with both the task and the material. They knew in advance how long the experiment would take. None of them complained about the number of scenarios they were required to judge. None of them complained about the believability of the scenarios. The research was approved by the university ethics committee, and a written informed consent was obtained from all the participants in the study.

\section{Results}

An analysis of variance (ANOVA) was performed on the whole dataset. The design 
was Participant Group (lay people vs health professionals) $\times$ Alcohol intake (no daily intake vs heavy drinker) $\times$ Tobacco consumption (non-smoker vs heavy smoker) $\times$ Degree of genetic proximity (uncle vs father) $\times$ Presence of incriminated gene (yes vs no) $\times$ Type of illness (lung cancer vs coronary artery disease vs RA). The main results are shown in Table 1. As we were running multiple comparisons, the significance threshold was set at .001.

Overall risk was judged by participants to be significantly higher: (a) for heavy alcohol intake $(M=9.13, \quad S D=1.73)$ than for abstinence $(M=7.59, \quad S D=1.67)$, (b) for heavy cigarette smoking $(M=9.97, S D=1.75)$ than for abstinence ( $M=6.74, S D=1.65)$, (c) when the relative was the father $(M=8.75$, $S D=1.61)$ rather than an uncle $(M=7.96$, $S D=1.66)$, (d) when a specific gene was present $(M=10.04, S D=1.96)$ than when it was absent ( $M=7.67,1.73)$ and (e) when the illness was coronary artery disease $(M=9.03$, 1.70) rather than lung cancer $(M=8.74$, $S D=1.71)$ or RA $(M=7.30, S D=1.89)$. A post hoc analysis using Tukey's honestly significant difference (HSD) test showed that only the difference between RA and the other two illnesses was significant.

Several two-way or three-way interactions involving risk factors were significant. The influence of tobacco consumption on risk judgements was weaker in the case of heavy alcohol intake (difference of 2.93 points between the highest and lowest levels) than in the case of abstinence (difference of 3.54). Similarly, the presence of the incriminated gene had a weaker effect on risk judgements in the case of heavy alcohol intake (difference of 3.13) than in the case of abstinence (a difference of 3.62). The presence of the incriminated gene had a weaker influence on risk judgements in the case of heavy tobacco consumption (difference of 3.00) than in the case of abstinence (difference of 3.75). In addition, the Alcohol intake $\times$ Tobacco consumption interaction was weaker when the incriminated gene was present than when it was absent.

Several two-way or three-way interactions involving the type of illness were also significant. The effect of alcohol intake on risk judgements was stronger for coronary artery disease (difference of 2.23) than for the other two illnesses (difference of 1.24). Tobacco consumption had a stronger influence on risk judgements for lung cancer (difference of 4.75) than for coronary artery disease (difference of 3.57), and a stronger influence for coronary artery disease than for RA (difference of 1.39). The presence of the incriminated gene had a stronger influence on risk judgements for RA (difference of 4.25) than for the other two illnesses (difference of 2.95). In addition, (a) the Alcohol intake $\times$ Tobacco consumption interaction was stronger for coronary artery disease than for the other two illnesses and (b) the Tobacco consumption $\times$ Presence of gene interaction was weaker for RA than for the other two illnesses.

Several two-way interactions involving the participant group factor were significant. The alcohol intake effect was stronger among lay people (difference of 1.92) than among health professionals (difference of 1.21). By contrast, the presence of the incriminated gene had a stronger effect among health professionals (difference of 3.72) than among lay people (difference of 3.03). Furthermore, the risk level associated with RA was lower among health professionals $(M=6.80, \quad S D=1.87)$ than among lay people $(M=7.79, S D=1.91)$, although there was no difference regarding either of the other two illnesses.

Table 1. Main results of the ANOVA.

\begin{tabular}{|c|c|c|c|c|}
\hline Factor & $d f M S$ & $F$ & $p$ & $\operatorname{Eta}_{p}^{2}$ \\
\hline $\begin{array}{l}\text { Participant Group } 1 \\
\text { (PG) }\end{array}$ & 1447.19 & 3.75 & .05 & .01 \\
\hline Alcohol intake (A) 1 & 16435.55 & 351.55 & .001 & .51 \\
\hline $\begin{array}{l}\text { Tobacco } \\
\text { consumption }(\mathrm{T})\end{array}$ & $1 \quad 27,549.67$ & 1413.13 & .001 & .81 \\
\hline
\end{tabular}




\begin{tabular}{|c|c|c|c|c|c|}
\hline $\begin{array}{l}\text { Degree of } \\
\text { proximity }(\mathrm{P})\end{array}$ & 1 & 1621.57 & 182.97 & .001 & .35 \\
\hline $\begin{array}{l}\text { Presence of gene } \\
\text { (G) }\end{array}$ & 1 & $30,030.66$ & 695.96 & .001 & .68 \\
\hline Type of illness (I) & 2 & 3007.69 & 205.26 & .001 & .38 \\
\hline$P G \times A$ & 1 & 332.69 & 18.17 & .001 & .05 \\
\hline $\mathrm{PG} \times \mathrm{T}$ & 1 & 97.27 & 4.99 & .03 & .01 \\
\hline $\mathrm{A} \times \mathrm{T}$ & 1 & 248.95 & 26.90 & .001 & .07 \\
\hline $\mathrm{PG} \times \mathrm{P}$ & 1 & 13.52 & 1.53 & .22 & .00 \\
\hline $\mathrm{A} \times \mathrm{P}$ & 1 & 0.11 & 0.03 & .86 & .00 \\
\hline $\mathrm{T} \times \mathrm{P}$ & 1 & 0.48 & 0.13 & .72 & .00 \\
\hline$P G \times G$ & 1 & 316.76 & 7.34 & .01 & .02 \\
\hline$A \times G$ & 1 & 159.43 & 33.93 & .001 & .10 \\
\hline $\mathrm{T} \times \mathrm{G}$ & 1 & 370.58 & 54.57 & .001 & .14 \\
\hline$P \times G$ & 1 & 22.35 & 6.49 & .01 & .02 \\
\hline $\mathrm{PG} \times \mathrm{I}$ & 2 & 243.12 & 16.59 & .001 & .05 \\
\hline$A \times I$ & 2 & 293.16 & 50.37 & .001 & .13 \\
\hline $\mathrm{T} \times \mathrm{I}$ & 2 & 2534.28 & 330.40 & .001 & .50 \\
\hline $\mathrm{P} \times \mathrm{I}$ & 2 & 7.86 & 2.45 & .09 & .01 \\
\hline $\mathrm{G} \times \mathrm{I}$ & 2 & 501.80 & 77.04 & .001 & .19 \\
\hline $\mathrm{PG} \times \mathrm{A} \times \mathrm{T}$ & 1 & 0.00 & 0.00 & .99 & .00 \\
\hline $\mathrm{PG} \times \mathrm{A} \times \mathrm{P}$ & 1 & 9.00 & 2.39 & .12 & .01 \\
\hline $\mathrm{PG} \times \mathrm{T} \times \mathrm{P}$ & 1 & 39.03 & 10.67 & .001 & .03 \\
\hline $\mathrm{A} \times \mathrm{T} \times \mathrm{P}$ & 1 & 1.91 & 0.48 & .49 & .00 \\
\hline$P G \times A \times G$ & 1 & 0.00 & 0.00 & .98 & .00 \\
\hline $\mathrm{PG} \times \mathrm{T} \times \mathrm{G}$ & 1 & 30.72 & 4.52 & .03 & .01 \\
\hline $\mathrm{A} \times \mathrm{T} \times \mathrm{G}$ & 1 & 177.31 & 44.55 & .001 & .12 \\
\hline$P G \times P \times G$ & 1 & 16.59 & 4.82 & .03 & .01 \\
\hline$A \times P \times G$ & 1 & 6.82 & 2.51 & .11 & .01 \\
\hline $\mathrm{T} \times \mathrm{P} \times \mathrm{G}$ & 1 & 13.16 & 4.02 & .05 & .01 \\
\hline $\mathrm{PG} \times \mathrm{A} \times \mathrm{I}$ & 2 & 16.78 & 2.88 & .06 & .01 \\
\hline $\mathrm{PG} \times \mathrm{T} \times \mathrm{I}$ & 2 & 264.39 & 34.47 & .001 & .09 \\
\hline $\mathrm{A} \times \mathrm{T} \times \mathrm{I}$ & 2 & 67.39 & 18.47 & .001 & .05 \\
\hline $\mathrm{PG} \times \mathrm{P} \times \mathrm{I}$ & 2 & 8.04 & 2.51 & .08 & .01 \\
\hline $\mathrm{A} \times \mathrm{P} \times \mathrm{I}$ & 2 & 6.28 & 2.04 & .13 & .01 \\
\hline $\mathrm{T} \times \mathrm{P} \times \mathrm{I}$ & 2 & 4.85 & 1.53 & .22 & .00 \\
\hline $\mathrm{PG} \times \mathrm{G} \times \mathrm{I}$ & 2 & 165.69 & 25.44 & .001 & .07 \\
\hline $\mathrm{A} \times \mathrm{G} \times \mathrm{I}$ & 2 & 6.66 & 2.15 & .12 & .00 \\
\hline $\mathrm{T} \times \mathrm{G} \times \mathrm{I}$ & 2 & 70.29 & 21.57 & .001 & .06 \\
\hline$P \times G \times I$ & 2 & 7.52 & 2.34 & .10 & .01 \\
\hline $\mathrm{PG} \times \mathrm{T} \times \mathrm{G} \times \mathrm{I}$ & 2 & 21.68 & 6.65 & .001 & .02 \\
\hline
\end{tabular}

ANOVA: analysis of variance.

The higher order interactions that were not significant are not reported here.

Several three-way and four-way interactions involving both the type of illness and the participant group factor were significant. For example, the effect of tobacco consumption varied more as a function of illness type among health professionals than among lay people.
Regarding RA, it was weaker among health professionals than among lay people, whereas in the case of lung cancer and coronary artery disease, it was stronger among health professionals than among lay people. Symmetrically, the effect of the presence of the incriminated gene varied more as a function of illness type among health professionals than among lay people. Regarding RA, it was stronger among health professionals than among lay people, whereas in the case of the other two illnesses there was no difference in strength. In addition, the Tobacco consumption $\times$ Presence of incriminated gene $\times$ Type of illness interaction was stronger among health professionals than among lay people (see Figure 1).

\section{Discussion}

This study examined the flexibility of lay people and health professionals when it comes to weighting behavioural and genetic risk factors in order to judge health risks in different conditions.

Our first hypothesis, confirmed by the data, was that all the risk factors would be employed by the participants. As expected, overall risk was judged to be higher in the case of heavy (vs low) daily intake of alcohol, in the case of daily (vs zero) tobacco consumption, when a family relative with the illness was genetically close (vs distant) and when the incriminated gene was present (vs absent). This result demonstrates that the participants understood the task and responded appropriately to the scenarios. There were, however, striking differences in the impact of the different factors on participants' risk judgements. Thus, the presence of the incriminated gene and daily tobacco consumption impacted on risk judgements far more than alcohol intake and family history did, explaining 46 and 42 per cent of the variance compared with 13 per cent for each the two remaining factors. 

JHP
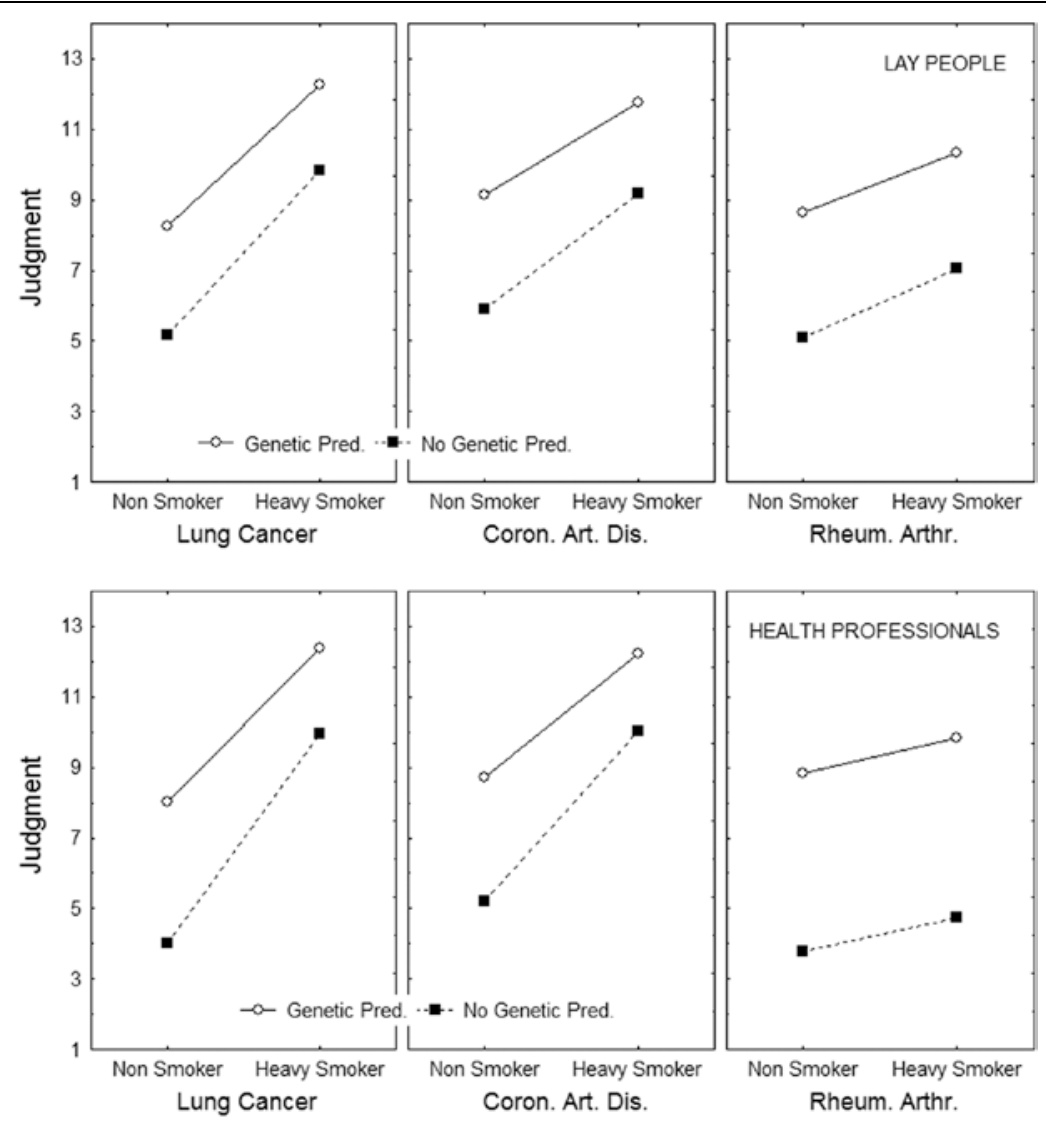

Figure 1. Pattern of results observed for lay people (top panels) and health professionals (bottom panels). In each panel, theaxis corresponds to the risk judgements, thexis bearshe two levels of tobacco behaviour, two curves correspond to the two levels of genetic predisposition and the three panels correspond to the three diseases.

Our second hypothesis, again confirmed by the data, was that the risk factors would be used in an interactive way. In addition to the
Alcohol $\times$ Tobacco interaction reported in earlier studies, we observed Alcohol $\times$ Gene, Tobacco $\times$ Gene 
Alcohol $\times$ Tobacco $\times$ Gene interactions. Where one of the factors (e.g. the presence of the incriminated gene) exerted a strong influence, the influence of the other factor(s) was correspondingly weaker. In other words, participants mentally combined the information in accordance with Rothman's (1976) antagonism model, and with the findings reported by Hermand et al., (1997). This way of thinking showed that people did not make much difference in the risk assessment when they add a second bad behaviour.

Our third hypothesis, which was broadly supported by the data, was that participants would be flexible in the way they employed the information in the three illness conditions. The flexibility demonstrated by people is in accord with epidemiological evidence, that is, they changed their weightings correctly. We expected the two behavioural risk factors (alcohol and tobacco) to have a greater impact for lung cancer than for RA, and the two genetic risk factors (family history and genetic test) to have a greater impact for RA than for lung cancer. When judging the risk of contracting lung cancer, participants did indeed rely mainly on daily tobacco consumption, just as they relied mainly on the genetic test results to judge the risk of RA. Finally, they relied more on alcohol intake in the coronary artery disease condition than they did in the other two conditions. The only risk factor that did not interact with type of illness was family history, but as we have already indicated, this factor had only a weak impact.

Our fourth hypothesis, fully supported by the data, was that the health professionals would be even more flexible than the lay people in weighting the risk factors. In the three cases mentioned in the previous paragraph, the Risk factor $\times$ Type of illness interaction was consistently stronger among the health professionals than among the lay people. In other words, the health professionals more gave weight to behavioural risk factors when judging the risk of contracting a behaviour-related illness, and additional weight to genetic-type factors when judging the risk of contracting a gene-related illness than the lay participants.

Two further series of findings deserve comment. The first one concerns the Group participant $\times$ Risk factor interactions: we found that genetic information had more impact in judging health risks among the health professionals than among the lay participants. This finding can be explained by the fact that health professionals are more frequently taught about the impact of genetics on the development of diseases than lay people are.

The second one concerns differences between the two groups in the strength of the Risk factor $\times$ Risk factor interactions: As can be observed in Figure 1, these interactions were stronger among the health professionals than among the lay participants. In other words, the former combined the health risk information in a more antagonistic way (Rothman, 1976) than the latter did. On the face of it, this is a paradoxical finding, as it suggests that health professionals are even further from the optimum model than lay people. More research is needed to resolve this paradox, but if it is confirmed, this way of thinking might affect their decision making and advice to their patients and would need to be rectified. As shown by Bonnin-Scaon et al., (2002), outcome feedback can help people to combine risk factors correctly.

Our study has several limitations. First, the participants were limited to the people of Toulouse, France. Generalizations to other countries must, therefore, be made with care. Second, the sample of physicians was very small in size. The study findings will, therefore, need to be confirmed on other samples. Third, although the influence of the genetics was shown beyond doubt in the occurrence of the present diseases, these are not at present detected by the practice of genetic tests in general medicine. At least, the ratings were made about hypothetical scenarios, rather than real cases. 


\section{Implications}

Our results highlight the way in which people combine information about environmental and genetic risk factors when judging the risk of developing lung cancer, coronary artery disease or RA. The implications are multiple. First, campaigns of prevention could be built from the way of thinking of the participants, notably to highlight the impact on health of interactions of multiple risks factors like tobacco, alcohol and genetics. Furthermore, as well as helping geneticists to adapt their explanations during their consultations, these results indicate that health professionals who are not specializing in genetics could be helped in their practice with a genetic in-house training.

\section{Funding}

This research received no specific grant from any funding agency in the public, commercial or not-forprofit sectors.[AQ 7]

\section{References}

Anderson NH (1982) Methods of Information Integration Theory. New York: Academic Press.

Ayanian JZ and Cleary PD (1999) Perceived risks of heart disease and cancer among cigarette smokers. JAMA 281: 1019-1021.

Bang SY, Lee KH, Cho SK, et al. (2010) Smoking increases rheumatoid arthritis susceptibility in individuals carrying the HLA-DRB1 shared epitope, regardless of rheumatoid factor or anticyclic citrullinated peptide antibody status. Arthritis and Rheumatism 62(2): 369-377.

Bonnin-Scaon S, Lafon P, Chasseigne G, et al. (2002) Learning the relationship between smoking, drinking alcohol, and the risk of oesophageal cancer. Health Education Research 17: 415-424.

Chibnik LB, Keenan BT, Cui J, et al. (2011) Genetic risk score predicting risk of rheumatoid arthritis phenotypes and age of symptom onset. Plos One 6(9): 1-7.

Claassen L, Henneman L, Der Weijden TV, et al. (2012) Being at risk for cardiovascular disease: Perceptions and preventive behavior in people with and without a known genetic predisposition. Psychology, Health \& Medicine 17(5): 511-521.
Claassen L, Henneman L, De Vet R, et al. (2010) Fatalistic responses to different types of genetic risk information: Exploring the role of selfmalleability. Psychology and Health 25(2): 183196.

Condit CM and Shen L (2011) Public understanding of risks from gene-environment interaction in common diseases: Implications for public communications. Public Health Genomics 14(2): $115-124$.

Gamm JL, Nussbaum RL and Bowles Biesecker B (2004) Genetics and alcoholism among at-risk relatives: Perceptions of cause, risk, and control. American Journal of Medical Genetics 128(2): 144-150.

Gränsbo K, Almgren P, Sjögren M, et al. (2013) Chromosome 9p21 genetic variation explains $13 \%$ of cardiovascular disease incidence but does not improve risk prediction. Journal of Internal Medicine 274(3): 233-240.

Guedj M, Gibert M, Maudet A, et al. (2005) The acceptability of ending a patient's life. Journal of Medical Ethics 31(6): 311-317.

Hermand D, Mullet E and Lavieville S (1997) Perception of the combined effects of smoking and alcohol on cancer risks in never smokers and heavy smokers. Journal of Health Psychology 2: 481-491.

Igier V, Sorum PC and Mullet E (2014) Judging patients' pain from external cues. Journal of Health Psychology 19(4): 570-573.[AQ 8]

Källberg H, Ding B, Padyukov L, et al.; EIRA Study Group (2011) Smoking is a major preventable risk factor for rheumatoid arthritis: Estimations of risks after various exposures to cigarette smoke. Annals of the Rheumatic Diseases 70(3): 508-511.

Kling JM, Miller VM, Mankad R, et al. (2013) Go red for women cardiovascular health-screening evaluation: The dichotomy between awareness and perception of cardiovascular risk in the community. Journal of Women's Health 22(3): 210-218.

Kozlowski LT and Ferrence RG (1990) Statistical control in research on alcohol and tobacco: An example from research on alcohol and mortality. British Journal of Addiction 85: 271-278.

Kulbertus H and Lancellotti P (2012) Atherosclerosis: A complex disease. Revue Médicale de Liege 67(5-6): 273-278. 
Lahiri M, Morgan C, Symmons DP, et al. (2012) Modifiable risk factors for RA: Prevention, better than cure? Rheumatology 51(3): 499-512.

Leighton JW, Valverde K and Bernhardt BA (2012) The general public's understanding and perception of direct-to-consumer genetic test results. Public Health Genomics 15(1): 11-21.

Markowitz SM, Park ER, Delahanty LM, et al. (2011) Perceived impact of diabetes genetic risk testing among patients at high phenotypic risk for type 2 diabetes. Diabetes Care 34(3): 568-573.

Marshall AL, Christiani DC (2013) Genetic susceptibility to lung cancer - light at the end of the tunnel? Carcinogenesis 34(3): 487-502.

Mattson ME, Pollack ES and Cullen JW (1987) What are the odds that smoking will kill you? American Journal of Public Health 77(4): 425431.

Molina JR, Yang P, Cassivi SD, et al. (2008) Nonsmall cell lung cancer: Epidemiology, risk factors, treatment, and survivorship. Mayo Clinic Proceedings 83(5): 584-594.

Muñoz Sastre MT, Bacq Y, Mullet E, et al. (2002) Misconceptions regarding hepatitis $C$ in the French public. Preventive Medicine 34(6): 596 600.[AQ 9]

Noonan D and Patrick ME (2013) Factors associated with perceptions of hookah addictiveness and harmfulness among young adults. Substance Abuse 34(1): 83-85.

Pun VC, Lin H, Kim JH, et al. (2013) Impacts of alcohol duty reductions on cardiovascular mortality among elderly Chinese: A 10-year time series analysis. Journal of Epidemiology \& Community Health 67(6): 514-518.

Rantala J, Platten U, Lindgren G, et al. (2009) Risk perception after genetic counseling in patients with increased risk of cancer. Hereditary Cancer in Clinical Practice 7(1): 15.

Rosengren A, Wilhelmsen L and Wedel H (1988) Separate and combined effects of smoking and alcohol abuse in middle-aged men. Internal Medicine 2: 111-118.
Rothman KJ (1976) The estimation of synergy dr antagonism. American Journal of Epidemiology 103: 506-511.

Rothman KJ and Greenland S (2005) Causation and causal inference in epidemiology. American Journal of Public Health 95(1): 144-150.

Saracci R (1987) The interaction of tobacco smoking and other agents in cancer aetiology. Epidemiologic Review 9: 175-193.

Smerecnik CM, Mesters I, de Vries NK, et al. (2009) Alerting the general population to genetic risk\$: The value of health messages communicating the existence of genetic risk factors for public health promotion. Health Psychology 28(6): 734 745.[AQ 10]

Sobenin IA, Chistiakov DA, Bobryshev YV, et al. (2013) Mitochondrial mutations in atherosclerosis: New solutions in research and possible clinical applications. Current Pharmaceutical Design 19(33): 59425953.[AQ 11]

University of California at Berkeley (2007) What not to believe. Wellness Letter 24(3): 3.

Vandelanotte C, Duncan MJ, Hanley C, et al. (2011) Identifying population subgroups at risk for underestimating weight health risks and overestimating physical activity health benefits. Journal of Health Psychology 16(5): 760769.[AQ 12]

Wang C, Miller SM, Egleston BL, et al. (2010) Beliefs about the causes of breast and colorectal cancer among women in the general population. Cancer Causes \& Control 21(1): 99-107.

Wang H, Zhao Y, Ma J, et al. (2013) The genetic variant rs $401681 \mathrm{C} / \mathrm{T}$ is associated with the risk of non-small cell lung cancer in a Chinese mainland population. Genetics and Molecular Research 12(1): 67-73. 


\section{Appendix 1}

\section{Two examples scenarios}

Mr Gibet is 42 years old. In his family, his father suffers from coronary artery disease. Mr Gibet only drinks alcohol on special occasions. He does, however, smoke more than a pack a day. Given his family history, his general practitioner arranges for him to undergo a genetic susceptibility test. The results indicate that Mr Gibet has the particular form of the gene potentially involved in this disease.

In your opinion, what is the risk of Mr Gibet developing coronary artery disease?

(15-point scale ranging from no risk at all to very high risk).

Mr Ribod is 45 years old. In his family, his father suffers from lung cancer. Mr Ribod regularly consumes large amounts of alcohol (the equivalent of more than a litre of wine per day). In addition, he smokes more than a pack a day. Given his family history, his general practitioner recommends a genetic susceptibility test. The results indicate that Mr Ribod does not have the particular form of the gene potentially involved in this disease.

In your opinion, what is the risk of Mr Ribod developing lung cancer?

(15-point scale ranging from no risk at all to very high risk) 